Trabalho recebido em 10/03/2008

Aprovado para publicação em 22/05/2009

\title{
NOVAS FUNÇÕES E NOVAS ATIVIDADES COMO ALTERNATIVAS DE DESENVOLVIMENTO DA AGRICULTURA FAMILIAR NO BRASIL
}

\author{
André Grossi Machado; David José Caume
}

\section{RESUMO}

O objetivo deste artigo é discutir alternativas de desenvolvimento da agricultura familiar no Brasil com um enfoque voltado aos conceitos de pluriatividade da agricultura familiar e multifuncionalidade do espaço agrário. Dentro dessa abordagem, e procurando comparar com a situação de outros países, objetiva-se explicar as especificidades, assim como as oportunidades e limitações da aplicação desses conceitos no país. A conjugação desses conceitos pode levar a um modelo sustentável de desenvolvimento rural, proporcionando a fixação e manutenção de famílias no campo ligadas a atividades como a agricultura orgânica, agroecologia, turismo rural, ecoturismo, artesanato e pequenos beneficiamentos de alimentos. Conclui-se que os formuladores de políticas voltadas ao desenvolvimento rural podem se beneficiar dessas idéias, e mais iniciativas deveriam ser tomadas relacionando os dois conceitos.

Palavras-chave: desenvolvimento rural, mutifuncionalidade, pluriatividade.

\section{NEW FUNCTIONS AND NEW ACTIVITIES AS DEVELOPMENT ALTERNATIVES TO FAMILY AGRICULTURE IN BRAZIL}

\begin{abstract}
The objective of this article is to discuss alternatives of the family agriculture development in Brazil with a focus on concepts of pluriactivity and multifunctionality in the agrarian space. Starting from those concepts, and trying to compare with other countries situations, we try to explain the specificities, as well as the opportunities and limitations of their application in our country. The conjugation of those concepts can take to a sustainable model of rural development, providing the staying and maintenance of families dedicated to activities as the organic agriculture, agroecology, rural tourism, eco-tourism, workmanship and small processing of foods in the countryside. We conclude that rural development policies makers can benefit of those concepts.
\end{abstract}

Key words: rural development, multifunctionality, pluriactivity

André Grossi Machado. Mestrando do Programa de Pós-Graduação em Agronegócio. Escola de Agronomia

e Engenharia de Alimentos. Universidade Federal de Goiás·E-mail: agrossim@yahoo.com.br

David José Caume. Professor Doutor do Programa de Pós-Graduação em Agronegócio. Escola de Agronomia

e Engenharia de Alimentos. Universidade Federal de Goiás. E-mail: caume@uol.com.br 


\section{INTRODUÇÃO}

O processo de modernização da agricultura brasileira transformou o país num dos maiores produtores e exportadores de produtos agrícolas, apresentando atualmente um dos maiores índices de produtividade e eficiência econômica no mercado mundial desses produtos. Entretanto, o modelo de desenvolvimento adotado não levou em conta aspectos ambientalmente sustentáveis e socialmente igualitários.

O cunho produtivista desse modelo baseado no uso intensivo de agroquímicos, exploração extrativista dos recursos naturais, emissão de resíduos sem nenhum controle e redução da biodiversidade através da expansão da fronteira agrícola e ocupação de novas áreas acaba por configurar sérios problemas ambientais. Já os problemas do ponto de vista social, decorrentes desse modelo, podem ser explicados pelo seu caráter excludente e conservador, onde se manteve a tradicional estrutura agrária concentrada, e os fartos recursos públicos foram claramente direcionados preferencialmente aos produtores considerados capazes de incorporar tecnologia e se adequarem ao processo de integração à indústria.

A herança de tal modelo excludente produziu uma clara divisão até entre os tipos de agricultores familiares no meio rural brasileiro. De um lado, agricultores altamente integrados à indústria à montante e à jusante, e, de outro, o restante dos agricultores, que vivem de uma economia de subsistência, comercialização de excedentes, mecanismos de assistencialismo e realização de outras atividades complementares. E, além desses dois grupos de agricultores familiares, cabe ressaltar o grupo de indivíduos que historicamente foram vítimas dos processos de exclusão no campo e que hoje figuram como agentes sociais em luta política através de representações como o Movimento dos Sem Terra (MST).

Diante da difícil inserção dos dois últimos grupos citados anteriormente, os agricultores familiares de base camponesa, e os sem-terra, na dinâmica e lógica das relações do agronegócio brasileiro, caracterizado pela produção de commodities e matérias-primas industriais, alta adoção de tecnologias e grande necessidade de capital, os conceitos de multifuncionalidade e pluriatividade podem ser úteis no direcionamento de políticas públicas. A utilidade vem na medida em que suas aplicações possibilitam novas alternativas de inserção econômica e social a esses agricultores, através do aumento das possibili- dades de geração de empregos, agrícolas ou não. Além disso, com a aplicação desses conceitos pode-se chegar a outros benefícios como a preservação e valorização ambiental, e a produção de alimentos mais saudáveis, através de técnicas de agroecologia ou agricultura sustentável, configurando possíveis soluções que atendam à crescente consciência mundial da necessidade de desenvolvimento de formas de produção sustentáveis, ecologicamente corretas e éticas do ponto de vista social.

O objetivo deste trabalho é discutir alternativas de desenvolvimento da agricultura familiar no Brasil, com um enfoque voltado aos conceitos de pluriatividade da agricultura familiar e multifuncionalidade do espaço agrário. Dentro dessa abordagem, e procurando comparar com a situação de outros países, objetiva-se explicar as especificidades, assim como as oportunidades e limitações da aplicação desses conceitos no país.

\section{A PLURIATIVIDADE NA AGRICULTURA FAMILIAR BRASI- LEIRA: LIMITES E POSSIBILIDADES}

Nas últimas décadas, as expressões agricultor em tempo parcial, atividades não agrícolas e pluriatividade fazem parte dos estudos e discussões acerca dos problemas envolvidos na questão do desenvolvimento rural principalmente nos Estados Unidos e Europa. No Brasil, o assunto desperta interesse de diversos pesquisadores desde o início da década de 1990 (Alves, 2002).

Segundo Anjos, (2003, apud Marafon 2006) a pluriatividade, ou a emergência de atividades não-agrícolas no meio rural, é um fenômeno onde famílias de agricultores tradicionalmente ocupadas com atividades estritamente agrícolas passam a desenvolver outras atividades como estratégia de complementação de renda. Essa complementação pode vir através da venda da força de trabalho familiar, da prestação de serviços, ou de iniciativas internas à propriedade como o turismo rural, o artesanato, diversificação na produção e pequenos beneficiamentos de seus produtos. Marafon (2006) ainda cita que tal fenômeno não deve ser encarado como uma situação nova, mas uma característica histórica importante de agricultores familiares, que sempre, no intuito de incrementar sua renda, desenvolveram atividades nãoagrícolas ou para-agrícolas (beneficiamento de alimentos e bebidas). Essas estratégias representam, portanto, características intrínsecas dos agricultores familiares. 
Essa estratégia, embora considerada por muitos como temporária ou esporádica, com o intuito de contra-balancear momentos de crise nas atividades agrícolas, pode se mostrar como uma característica estrutural de certos agricultores familiares, devido ao contexto em que eles estão inseridos e conseqüentemente às contingências a que eles são submetidos.

Com a crescente integração entre campo e cidade e o fluxo de populações tipicamente urbanas para o meio rural, tal fenômeno se evidencia mais ainda. O espaço rural passa a ter novas formas de desenvolvimento, com novas possibilidades de emprego através de atividades de lazer caracterizadas pela crescente procura por turismo rural, ecoturismo e clubes campestres, e também pela demanda crescente por moradias no campo por pessoas das cidades, com a construção de condomínios, sítios e chácaras.

Como conseqüência, oportunidades de prestação de serviços surgem na medida em que novas formas de lazer e ocupação aparecem no campo, como na construção civil, nas atividades de caseiro, jardineiro, cozinheiro, motoristas, etc, além de empregos nos pequenos comércios que surgem para atender as demandas desses novos atores no meio rural, as populações tipicamente urbanas. Além disso, configurando o extremo da redefinição do espaço rural e da oportunidade de novas ocupações, observa-se o processo de migração de unidades fabris para o campo decorrentes de processos de descentralização da indústria. Todos esses fatores ajudam a configurar o que alguns autores como Graziano da Silva (2002) chamam de o "novo rural", ou o processo de "urbanização do rural", aonde a tradicional oposição campo/cidade vai perdendo importância e significado. Esse mesmo autor considera que o fenômeno da emergência de atividades tipicamente urbanas no meio rural indica um processo gradativo e crescente de "desidentificação" do meio rural com a agricultura.

O aumento de atividades não-agrícolas ou não tipicamente agrícolas pode ser observado tanto em países em desenvolvimento como também em países desenvolvidos. Esse fenômeno ilustra tanto a capacidade e necessidade de agricultores familiares não totalmente inseridos na moderna dinâmica agroindustrial e de mercado de criarem saídas para problemas advindos do caráter excludente que caracterizou a evolução da agricultura nos últimos anos e conformou o agronegócio mundial, como também, e acima de tudo, ilustrar a busca de alternativas para o desenvolvimento e a continuidade da família no meio rural.
Analisando as regiões "essencialmente rurais", em países desenvolvidos como Estados Unidos, França, Austrália, Japão entre outros, Schneider (2003) mostra, através de dados da Organização para Cooperação e Desenvolvimento Econômico (OCDE), que entre 1980 e 1996, na maioria desses países, as taxas de crescimento anual do emprego agrícola foram negativas, enquanto as taxas de crescimento dos empregos não-agrícolas se mostraram positivas. O mesmo autor cita algumas das possíveis causas da emergência de atividades não-agrícolas nos países desenvolvidos, como sendo: a modernização tecnológica com sua capacidade de excluir alguns agricultores e de poupar mão-de-obra de outros, liberando integrantes das famílias de agricultores para outras atividades; a queda na renda agrícola; as políticas públicas que buscam fomentar a "desintensificação" da atividade agrícola, caracterizando a importância dada à questão da multifuncionalidade do espaço agrário; a dinâmica do mercado de trabalho não-agrícola caracterizada pelos processos de descentralização industrial em áreas rurais; e a própria pluriatividade como característica estrutural da agricultura familiar, onde famílias tradicionalmente sempre desempenharam atividades não-agrícolas dentro das propriedades, como o artesanato.

No Brasil, através de dados das Pesquisas Nacionais por Amostras de Domicílios (PNADs), referentes à década de 90, Graziano da Silva (2002) constata situação semelhante: uma pequena taxa de crescimento $(0,7 \%$ ao ano) da população domiciliada no meio rural e ocupada em atividades agrícolas, contrastando com uma taxa relativamente maior de crescimento $(5,4 \%$ ao ano) da população domiciliada no meio rural e ocupada em atividades não-agrícolas.

No caso brasileiro, algumas causas para essa situação guardam semelhanças com as dos países desenvolvidos, excetuando-se algumas questões. No Brasil, diferentemente do exemplo europeu, praticamente inexistem políticas de incentivo à manutenção do agricultor no campo sem desempenhar atividades necessariamente agrícolas caracterizadas pela abordagem multifuncional do espaço agrário. E, o mais importante, a dinâmica do mercado de trabalho não-agrícola, ou seja, as atividades alternativas que surgem no campo brasileiro são totalmente diferentes das que surgem no meio rural de países desenvolvidos. Quanto às outras causas há bastante semelhança.

O processo de modernização tecnológica da agricultura no Brasil também colaborou para a pluriatividade, 
tanto do ponto de vista dos agricultores excluídos que não tiveram condições de adotar os pacotes tecnológicos, como dos trabalhadores rurais ou membros de famílias de agricultores que foram poupados devido às novas funções desenvolvidas pelas máquinas. A queda na renda agrícola no Brasil também se conforma como uma causa, principalmente devido ao esgotamento da oferta de crédito pelo Estado no fim dos anos 1980, a equiparação cambial com o dólar no início do Plano Real, o controle da inflação baseado no controle de preços de alimentos, e a abertura comercial promovida pelo governo no início dos anos 1990.

Pode-se citar ainda a intensa integração cidade/campo que cria novas oportunidades de ocupação e a já citada característica estrutural da agricultura familiar: a constante criação de estratégias complementares de geração de renda não necessariamente agrícolas.

Portanto, a tendência do aumento das atividades nãoagrícolas no Brasil pode levar ao entendimento de que existem outras formas e possibilidades de atividades econômicas e empregos, para os agricultores excluídos no nosso meio rural. As possibilidades surgem devido a uma maior integração com o meio urbano, dada a evolução dos meios de transporte e comunicação, maior valorização do estudo nas áreas urbanas por parte de membros mais novos de famílias tipicamente rurais, melhora relativa da infra-estrutura no meio rural, com energia elétrica, estradas, pontes, desenvolvimento de pequenos comércios, centros de saúde, escolas, etc.

Todavia, cabe ressaltar que, pelo fato do processo de integração do meio rural com o meio urbano, e, conseqüentemente, o aumento das opções para que uma família de agricultores se torne pluriativa necessitar de infra-estrutura e condições básicas de desenvolvimento humano, deve-se considerar as enormes variações dentro do território brasileiro. Ao mesmo tempo em que as regiões Sul e Sudeste têm enorme potencial de contribuir com essa integração e com novas oportunidades de ocupação, ainda que com exceções, as demais regiões, principalmente, o Norte e o Nordeste, possuem claras carências estruturais para tanto.

Apesar das carências, a maioria dos agricultores familiares da região Nordeste, segundo Alves (2002), por não ter participado do processo de modernização da agricultura brasileira, além de viverem de recursos previdenciários e outros recursos públicos assistencialistas, recorrem sempre a atividades complementares com o objetivo de sobrevivência e manutenção de suas famílias no campo.

Não só no Nordeste, mas em todo país observa-se esse fenômeno, como foi descrito anteriormente, e eles guardam um ponto em comum, a necessidade de complementar renda e propiciar o desenvolvimento de suas famílias. O grande problema é que há a necessidade de se diferenciar ocupações dignas e de boa remuneração com ocupações pouco valorizadas e exploratórias. E o que pode delimitar as oportunidades diferenciadas são justamente as características naturais e estruturais das regiões, de educação, saúde, moradia, economia, cultura, clima, entre outras.

Tal fato mostra que a emergência de atividades nãoagrícolas na agricultura familiar do Brasil pode ter duas faces: oportunidades devido ao surgimento de boas ocupações valorizadas no meio rural, como comércio, lazer, indústria e serviços especializados, associadas a um processo de maiores oportunidades de educação fundamental, média e superior, e, no oposto, oportunidades forçadas, indignas, exploratórias, pouco valorizadas e remuneradas. $\mathrm{O}$ que pode ser caracterizado para alguns produtores familiares como uma escolha vantajosa frente a alternativas presentes e concretas, também pode ser encarado como uma solução única e sofrida de sobrevivência para outros, decorrentes de condições extremamente desfavoráveis de se desenvolver a agricultura.

Considerando ainda o apego à terra, característica fundamental de agricultores, Alves (ibid.) coloca um ponto importante: verifica que, para alguns agricultores do sertão nordestino, empregos considerados "bicos" podem, muitas vezes, representar um fracasso, um sofrimento, e são encarados como uma incapacidade de continuar na atividade agrícola.

Portanto, mesmo verificando-se a importância das atividades não-agrícolas no Brasil e a crescente integração do rural com o urbano, não se pode generalizar e creditar a essa fórmula a solução dos problemas sociais no campo. Para alguns, aplicar essa fórmula, por exemplo, aos Trabalhadores Sem-Terra pode ser uma das saídas para a reforma agrária, ou seja, caracterizar uma reforma social não essencialmente do ponto de vista agrícola, mas sim através da criação de empregos oriundos dessa nova onda da "urbanização do rural”. Mas como o próprio "novo rural" compreende a pluriatividade dentro das propriedades, através do artesanato, pequenos beneficiamentos, turismo, e até atividades com um certo vínculo agrícola, como a produção para nichos de mercado, pro- 
dução orgânica e agroecologia, não se deve abandonar a idéia de uma reforma social e um fortalecimento da agricultura familiar com um cunho de distribuição de propriedade da terra.

O assunto em questão é foco de muitos debates por parte de pesquisadores brasileiros da área. Segundo Graziano da Silva (2002), há muitos problemas no processo de redistribuição de terras e a oferta de alimentos já é suprida pela agricultura patronal com eficiência, e por isso, nossa reforma agrária não precisa ter um caráter essencialmente agrícola, e sim combinar atividades que demandem menos terras, através de ocupações como: construção de casas populares, serviços de caseiros em regime de comodato, serviços de guardas ecológicos, guias turísticos e de artesanato. Atividades, segundo o autor, que não precisam de muito nível de qualificação e que podem ser difundidas através de treinamentos rápidos.

Já para Wanderley (2002, apud Machado 2005), terra não seria obstáculo, pois os espaços vazios de áreas improdutivas são um grande problema, e a reforma agrária ainda se mostra necessária para resolver a questão da distribuição de terra e exclusão social no Brasil. Também interpreta os assentamentos de Sem-Terra como "sementeiras" de agricultores familiares, que, para a autora, são os principais personagens do campo e têm um papel fundamental enquanto produtores, necessitando de estratégias e políticas de desenvolvimento rural que reconheçam essa importância. No lugar de espaços vazios e improdutivos, se estabeleceriam comunidades agrícolas que ajudariam a preservar e valorizar o patrimônio natural e cultural do meio rural.

Guanziroli (2001) também segue a mesma linha e observa que os dados das PNADs referentes às rendas e atividades não-agrícolas no Brasil não conseguem explicar as razões e tendências da pluriatividade como acontece na Europa. Considera muito mais fácil esse fenômeno no Brasil representar estratégias de "refúgio" provenientes da total falta de condição de desempenhar uma agricultura integrada ao mercado e à indústria e, portanto, também defende uma reforma agrária com um foco agrícola. O autor faz uma ressalva de que toda boa oportunidade de ocupações não-agrícolas deve ser também considerada.

Enquanto de um lado, acredita-se que a solução seria manter a atual estrutura agrária concentrada e o papel de produtores de alimentos para os agricultores patronais, levando as soluções não-agrícolas para os atores excluídos do campo; de outro, defende-se a idéia de que a re- forma agrária e o fortalecimento da agricultura familiar ou pequena agricultura ainda têm um papel importante a desempenhar, do ponto de vista econômico e mais ainda social. A última corrente se aproxima muito da estratégia que os europeus adotam para sua agricultura.

Portanto, mesmo observando a existência de possibilidades de empregos e ocupações valorizadas com nenhum vínculo à produção agrícola, segue-se que a idéia distributiva da reforma agrária com o foco agrícola não pode ser deixada de lado. Isso se deve principalmente a ainda clara existência de enormes extensões de terra improdutivas no Brasil, e a constatação de que muitas atividades não-agrícolas podem representar um "refúgio" para o agricultor. Recorre-se, portanto, à realidade de heterogeneidade das características, potenciais e condições de vida no meio rural do Brasil, demandando soluções diferenciadas.

O mais importante é, que o fenômeno da pluriatividade pode, diante da crescente preocupação mundial com o meio ambiente e através de políticas direcionadas, levar a uma reorientação do modelo de desenvolvimento do meio rural brasileiro. A reorientação pode vir por meio de um modelo auto-sustentável, ecologicamente correto e socialmente igualitário, proporcionando a fixação e manutenção de famílias no campo ligadas a atividades como a agricultura orgânica, agroecologia, turismo rural, ecoturismo, práticas de esporte ligadas à natureza, artesanato e pequenos beneficiamentos de alimentos. Todas essas atividades fortemente incentivadas por práticas de associativismo e de mecanismos de extensão e capacitação.

Portanto, há a possibilidade de se conciliar a redistribuição de terras e programas de fomento à agricultura familiar com atividades agrícolas ou não, voltadas para uma noção diferente de ocupação do território rural, a noção de multifuncionalidade do espaço agrário. Através desse enfoque, muito valorizado e apoiado atualmente na Europa, pode-se resolver ao mesmo tempo os problemas ambientais advindos do caráter produtivista de desenvolvimento, e os problemas sociais de má distribuição de riquezas e desemprego no Brasil.

\section{A MULTIFUNCIONALIDADE DO ESPAÇO AGRÁRIO: ALTERNATIVAS PARA O BRASIL}

O termo multifuncionalidade da agricultura surgiu durante a conferência mundial Rio Earth Summit, em 1992, 
na cidade do Rio de Janeiro, onde representantes de vários países discutiram assuntos relacionados ao desenvolvimento sustentável, que culminou, entre outros frutos, na elaboração do documento conhecido como Agenda 21. Nesse documento, o termo "agricultura multifuncional" era entendido como uma atividade que respeitasse a segurança alimentar e o desenvolvimento sustentável, ou seja, uma atividade que, além de cumprir seus objetivos tradicionais de produção de alimentos e fibras, produzisse externalidades positivas como respeito ao meio ambiente e à biodiversidade, preservação da qualidade do ar e da água, conservação dos solos e produção de bioenergia, e que proporcionasse, entre outros benefícios, a viabilidade e o desenvolvimento de comunidades rurais e a valorização de suas paisagens (DeVries, 2000).

Mesmo que as discussões sobre o que as externalidades positivas da agricultura poderiam fornecer à sociedade já tivessem seu início anos antes, é a partir desse encontro que fica clara a preocupação de vários países em adotar métodos mais sustentáveis em suas agriculturas. Mas, na prática, os discursos acabam sendo esquecidos, principalmente por países em desenvolvimento, com menores capacidades de articulações de políticas, poucos recursos que possam ser investidos, e a existência de enormes influências ou lobbies no governo por parte de grandes agricultores e industriais.

Conseqüentemente, esses países em desenvolvimento foram os primeiros a rejeitar o conceito de multifuncionalidade quando ele foi um dos assuntos da reforma na Política Agrícola Comum (PAC) de 1992 na Europa.

De acordo com Abramovay (2002) e DeVries (2000), a reforma na PAC européia, que incluía a mudança de seu mecanismo estatal de sustentação de preços por ajudas diretas à atividades multifuncionais da agricultura, e a argumentação e pedido não só da União Européia, mas de países como o Japão e a Coréia do Sul da inclusão de aspectos multifuncionais nos acordos sobre agricultura na Organização Mundial de Comércio (OMC), fizeram com que os principais países exportadores de alimentos, inclusive o Brasil, organizados no Grupo de Cairns, entendessem que isso levava, sem dúvida alguma a uma tentativa de encobrir ou dar uma nova roupagem aos mecanismos de protecionismo e subsídios aos seus agricultores.

Essa preocupação é compreensível na medida em que esses países travam uma constante luta na OMC com relação aos subsídios agrícolas. Mas é preciso entender que é justamente esse aspecto que diferencia a noção de agricultura de países em desenvolvimento e de países desenvolvidos. Na Europa, por exemplo, a agricultura sempre foi elemento estratégico de desenvolvimento econômico e social justo, cabendo ao estado subsidiar e ajudar sim seus produtores. No Brasil, representando o outro extremo, o discurso de liberalismo econômico associado a uma evidente incapacidade atual de atuação estatal na agricultura, produz uma intensa concentração de capital e terra, formando um cenário de contraste com a divisão entre agricultores empresariais e pequenos agricultores marginalizados, compondo cada vez mais a massa de desempregados e objetos de políticas assistencialistas.

Os subsídios sempre existiram na Europa e a preocupação não deve se voltar a eles, e sim ao reconhecimento de que o conceito de multifuncionalidade da agricultura é uma tendência de preocupação com o meio ambiente, com os agricultores familiares e do que ela pode proporcionar à sociedade. Para Abramovay (2002), apesar de toda discussão comercial entre países, não se pode negar a existência da preocupação cada vez maior com os objetivos não produtivos da agricultura na Europa, baseados nas outras funções que ela pode exercer para a sociedade. Nesse sentido, a multifuncionalidade da agricultura representa na Europa uma preocupação muito maior que a simples estratégia de proteger seus agricultores via subsídios.

Segundo Abramovay (ibid.p. 17), a França é um dos bons exemplos da importância que se dá a tal fenômeno, com os Contratos Territoriais de Exploração (CTE's), experiência do governo socialista francês que apóia atividades como a "preservação da paisagem e patrimônio natural como também a própria vitalidade do tecido social rural".

Esses contratos entre agricultores e Estado acabam por representar um mecanismo de desenvolvimento voltado à manutenção das populações ainda no meio rural, não precisando, necessariamente, se ocuparem com atividades estritamente agrícolas. Isso já é um fato na França, país tradicionalmente conhecido por sua importância na produção agrícola, ocupando altas posições no comércio europeu e mundial desses produtos, e que hoje se defronta com um novo cenário, o da diminuição da população rural ocupada com atividades agrícolas.

Esse fenômeno é ilustrado por Schneider (2003, p. 122), onde ele mostra que a população agrícola ativa na França "caiu de 2,4 pessoas por propriedade rural em 
1970 para uma média de 1,4 pessoas em 1993" e mais ainda, que "entre 1970 e 1985 o conjunto da população agrícola ativa caiu de $15 \%$ para $7 \%$ ”.

Os números acima podem ser explicados pelo surgimento de alternativas não-agrícolas, como estratégias de complementação de rendas para os tradicionais agricultores, e, nesse sentido, a multifuncionalidade do espaço rural na França é entendida e fomentada como possibilidade, ou até elemento favorecedor da conciliação entre o fenômeno da pluriatividade dos agricultores com a sua manutenção e permanência no meio rural.

Logo, o modelo francês pode ser útil, na formulação e discussão de políticas públicas no Brasil que visam atender aos problemas decorrentes da falta de oportunidade de atores excluídos no meio rural brasileiro. Por ser o conceito de multifuncionalidade claramente ligado a um "espaço" ou território, ele pode ajudar nas políticas de inserção social no Brasil, como por exemplo, a reforma agrária, num contexto mais amplo de oportunidades não ligadas estritamente à produção agrícola, mas talvez a outras atividades ligadas ao campo, como o turismo rural e o ecoturismo através de hotéis e pousadas fazendas, centros de esportes ligados à natureza, colônias de férias rurais, pólos de artesanatos, pequenas agroindústrias, entre outras, todas elas ligadas a uma valorização ambiental e cultural de sua região. É importante ressaltar que soluções agrícolas para problemas de inserção social no meio rural também podem e devem ser estimulados sob a ótica da multifuncionalidade, sendo primordial a preocupação em "como produzir", ou seja, conciliar a produção agroalimentar com práticas ecologicamente corretas e sustentáveis, e que priorizem a relação e o respeito do homem com a natureza. Essa ressalva é feita, novamente, pelo argumento da diversidade de características, potenciais, expectativas e demandas do agricultor familiar no Brasil, levando a um entendimento da importância da relatividade de alternativas possíveis e discutíveis, não sendo produtivo generalizar fórmulas ou soluções.

Contudo, o Estado deveria direcionar suas ferramentas de apoio num sentido de reconversão ou reorientação do modelo de desenvolvimento tradicional pelo menos em alguns territórios. Machado (2005) argumenta que, para tanto, deve haver uma distinção entre território produtivista e território multifuncional, ou seja, aplicar e orientar políticas a alguns espaços do território brasileiro, criando oportunidades para agricultores familiares em dificuldade e assentamentos de reforma agrária, através de atividades fomentadas pela idéia multifuncional do espaço agrário.

Com isso, conciliar-se-ia o fortalecimento da agricultura familiar, a realização da reforma agrária e o fomento a atividades de preservação e valorização do espaço rural, da natureza e das paisagens, proporcionando ,ao mesmo tempo, condições de se desenvolver a pluriatividade e a permanência do homem no campo.

\section{CONCLUSÕES}

A característica pluriativa estrutural dos agricultores familiares é uma realidade, e nesse sentido acaba por facilitar e aumentar a gama de opções e soluções para suas dificuldades. Entretanto, apesar de procurar outras alternativas de geração de renda, o agricultor nem sempre encontra a satisfação pessoal ou até mesmo a complementação de renda esperada. Há regiões no Brasil claramente mais desenvolvidas e que, portanto, oferecem inúmeras oportunidades não-agrícolas atraentes e valorizadas às famílias de agricultores, enquanto em outras regiões a mesma estratégia não se deve à atratividade de outras atividades, mas sim a uma total impossibilidade de continuar na agricultura, levando a ocupações exploratórias e desvalorizadas. Logo, a pluriatividade não deve ser encarada como a solução para todos.

Além disso, mesmo com a clara existência de alternativas externas às propriedades de ocupação nãoagrícolas, que colaboram para a pluriatividade, mecanismos de redistribuição de terras e manutenção do homem no campo empenhado em atividades agrícolas ainda são de extrema importância como estratégia social de desenvolvimento. Uma agricultura familiar forte pode até ser elemento favorecedor da criação natural de outras oportunidades. É também uma chance de se aplicar, mesmo que tardiamente, soluções sustentáveis e ecologicamente corretas de desenvolvimento para o meio rural no Brasil. Soluções estas capazes de serem realizadas por agricultores familiares, colocando em prática idéias semelhantes às européias, que consideram tais agricultores como elementos chave para a preservação da natureza, das paisagens, do patrimônio natural e cultural, e responsáveis pelo fornecimento de alimentos mais saudáveis.

Todas essas idéias convergem para o enfoque da mul- 
tifuncionalidade, e este enfoque como atributo de um espaço ou território dá novas funções à propriedade rural, cria maiores oportunidades e alternativas de atividades dentro dela, ou seja, facilita a pluriatividade de agricultores, permite condições de vida dignas para seus habitantes, e com isso, proporciona benefícios para toda sociedade. Logo, a contemplação desse enfoque deveria ajudar a direcionar o processo e as discussões de reforma agrária e de estratégias de desenvolvimento da agricultura familiar.

As soluções não são fáceis e o trabalho do governo deve orientar-se pelas especificidades de cada caso. $\mathrm{O}$ próprio Programa Nacional de Fortalecimento da Agricultura Familiar (PRONAF), mesmo com suas limitações e distorções, devido à sua operacionalização por entidades bancárias, e conseqüente criação de barreiras a alguns agricultores, vem mostrando iniciativas que refletem a necessidade de variadas formas de solução, inclusive dentro do enfoque multifuncional da propriedade.

As iniciativas podem ser visualizadas através de linhas de financiamento, como o PRONAF Mulher, que estimula o artesanato e pequenos beneficiamentos de alimentos; PRONAF Jovem, PRONAF Turismo Rural, PRONAF Agroecologia, PRONAF Infra-estrutura, PRONAF Capacitação, PRONAF Floresta, PRONAF SemiÁrido, além de incentivos à extensão rural e à pequena agroindustrialização de produtos agrícolas, estímulos a práticas associativas dos produtores, e fornecimento de créditos diferenciados (PRONAF 2005).

Entretanto, apesar da evolução do PRONAF e de outros esforços do governo, mais iniciativas deveriam ser tomadas associando os conceitos de multifuncionalidade e pluriatividade, ou seja, relacionando aspectos econômicos, sociais e ambientais. Considera-se que os formuladores de políticas podem se beneficiar dessas idéias, conjugando iniciativas de reforma agrária e fortalecimento da agricultura familiar com uma reorientação estratégica do modelo de desenvolvimento rural, através de uma agricultura e espaço agrário auto-sustentáveis que possam proporcionar novas atividades e condições dignas de vida para as famílias de agricultores e desempenhar novas funções para a sociedade.

\section{REFERÊNCIAS BIBLIOGRÁFICAS}

ABRAMOVAY. R. Subsídios e multifuncionalidade na política agrícola européia. Economia Rural vol. 40, nº 2: 235-264. 2002. Disponível em <http://www.econ.fea.usp.br/abramovay/ artigos_cientificos/2002/Subsidios_multifuncional.pdf $>$. Acesso em: 20 de maio de 2006.

ALVES, M. O. Pluriatividade no sertão nordestino: uma estratégia de sobrevivência. O caso do município de Tejuçuoca, estado do Ceará. Revista Raízes, v. 21, n. 1. 2002 Disponível em $<$ http://www.bnb.gov.br/content/aplicacao/etene/artigos/docs/ pluriatividade_sertão_\%20nordestino.pdf $>$ Acesso em: 22 de maio de 2006.

DEVRIES, B. Multifunctional Agriculture in the International Context:A Review. Land Stewardship Project. 2000. Disponível em $<$ http://www.landstewardshipproject.org/mba/MFAReview.pdf $>$. Acesso em: 18 de maio de 2006.

GRAZIANO DA S., J. O novo rural brasileiro. Campinas, Instituto de Economia/UNICAMP. 2002.

GUANZIROLI, C., et al. Agricultura familiar e reforma agrária no século XXI. Rio de Janeiro, Garamond, 2001.

MACHADO, G. B.. Reforma agrária e multifuncionalidade do espaço rural. In: XLIII Congresso Brasileiro de Economia e Sociologia Rural, 2005, Ribeirão Preto - SP. (CD ROM). SOBER. 2005.

MARAFON, G. J. Agricultura familiar, pluriatividade e turismo rural: reflexões a partir do território fluminense. Campo-Território: Revista de Geografia Agrária, v. 1, n. 1. Uberlândia, 2006.

PRONAF. Plano de Safra 2005/2006. Ministério do Desenvolvimento Agrário. Secretaria de Agricultura Familiar. 2005. Disponível em < http://www2.faep/docs/pronaf_2005.pdf> . Acesso em: 01 de junho de 2006.

SCHNEIDER, S. A pluriatividade na agricultura familiar brasileira. Porto Alegre: UFRGS, 2003. 